\title{
Compromised quality of maternal healthcare in a market economy: Medellín, Colombia 2008-2009
}

\author{
Gloria Molina, PhD¹, Gilma Vargas, MSN², Alina Shaw, BA ${ }^{3}$
}

\section{SUMMARY}

Objective: To analyze the quality of the maternal health services in Medellín city, Colombia within the context of the Social Security System in Health from the perspective of the mothers, physicians and nurses involved in the provision of these services.

Methodology: A qualitative study was carried out, during which 24 individual interviews were conducted to key doctors and nurses, who work in health institutions that providing maternal care. Also three focus groups with mothers were conducted. The data analysis was carried out using a systematic and carefully coding and categorization process.

Findings: In spite of the fact that municipal policies have been put in place to improve maternity care, mother and pregnant women face problems with health services. Findings suggests that the strategies put in place by these health institutions to decrease labor costs, the administrative barriers, the low tariffs of the obstetric services paid by the health insurers within and competitive market, and the focus on getting financial profitability, are aspects that affecting quality of maternal care.

Keywords: Health systems; Maternal health services; Maternal and child health; Quality health care.

Colomb Med. 2011; 42: 294-302

La calidad de servicios maternos en un ambiente de mercado: Medellín, Colombia 2008-2009

\section{RESUMEN}

Objetivo: Analizar la calidad de los servicios maternos en la ciudad de Medellín, Colombia, en el Sistema General de Seguridad Social en Salud, desde la perspectiva de la madres usuarias de los servicios maternos y del personal involucrado directamente en la prestación de estos.

Metodología: Se llevó a cabo un estudio con enfoque cualitativo; se realizaron 24 entrevistas individuales a médicos y enfermeras que prestan servicios maternos y se llevaron a cabo tres grupos focales con maternas embarazadas o en período de posparto. El análisis de la información se realizó mediante un proceso sistemático de codificación y categorización.

Hallazgos: A pesar de las políticas internacionales, nacionales y municipales puestas en marcha para mejorar la atención materna y perinatal, las madres enfrentan constantes problemas de acceso y calidad en los servicios. Son aspectos que afectan negativamente la calidad de la atención los mecanismos de contención de los costos de personal que aplican las diferentes instituciones, las barreras administrativas, las bajas tarifas por los servicios obstétricos que pagan las aseguradoras en un mercado competitivo y la búsqueda de rentabilidad financiera.

Palabras clave: Sistema de salud; Servicios de salud maternos; Salud materno-infantil; Calidad de la atención de salud.

Colomb Med. 2011; 42: 294-302

1. Associate Professor, Facultad Nacional de Salud Pública, Universidad de Antioquia, Medellín, Colombia. e-mail: molinag@saludpublica.udea.edu.co

2. Professor, Facultad Nacional de Salud Pública, Universidad de Antioquia, Medellín, Colombia. e-mail: gilmavargas@saludpublica.udea.edu.co

3. MPH Candidate, Emory University, Atlanta, USA. e-mail: alina.shaw@gmail.com Received for publication August 10, 2010 Accepted for publication April 17, 2011 
Since the mid-1970s, the Colombian healthcare system has undergone important changes. The National Healthcare System operated between 1974 and 1993, during which time the health of the country improved due to its focus on providing preventative programs. This was shown through the impressive reduction of maternal mortality rates from 310 per 100,000 in $1956^{1}$ to 86.3 in 1985 and down to 68.2 in $1993^{2}$. However, at the end of the 1980s and start of the 1990s, the downturn in the global economy resulted in economic restrictions such as structural adjustment dictated by international agencies, which affected developing countries like Colombia ${ }^{3}$. As a result, the role of the state was reduced through the decentralization and privatization of services. In response to these pressures, the Sistema General de Seguridad Social en Salud (SGSSS, in Spanish. Social Security System in Health), was created in 1993. Colombia's goal was to increase coverage, access, quality, and financial sustainability of the nation's public healthcare sector. A national insurance system was implemented as a way to increase access to health services. Subsidies of care were based on demand rather than on supply; thus, generating strategies of privatization, competition betweeninsurance companies and service providers, and the resources allocated to health care increased from $1.9 \%$ of the GDP in 2000 to $3.4 \%$ in $2006^{4}$, which in turn was intended to incentivize the efficiency, productivity, and profitability of the system. Instead, the development of programs for prevention and health promotion decreased because these programs were not profitable in the short term nor were they financially feasible for the state as an investor. Consequently, the country experienced several setbacks in public health initiatives. This was especially the case in maternal mortality, which increased from 66.2 in 1993 to 105 in $2000^{2}$.

In 2005, the maternal mortality rate in Medellin was 42 per 100,000. Although this was a lot lower than the mortality rates in other regions throughout Colombia, most of these deaths were preventable ${ }^{5}$. The primary causes for maternal deaths are related to the socioeconomic conditions of the women, the low quality of health services they receive (such as lack of prenatal care or inadequate care during delivery), and the mother's failure to recognize danger signs, among others, as indicated by higher rates of maternal morbidity than of maternal mortality.
Maternal morbimortality serves as a performance indicator of the quality of services offered by a health system. Given that morbidmortality evaluates the births attended by qualified staff, it assumes that fewer complications and deaths should occur during births attended by trained attendants ${ }^{6}$. Despite the maternal morbidmortality taking place in Medellín, 2007 DHS $^{7}$ data show that $95 \%$ of maternal care was provided by qualified staff. After it was created, the SGSSS reportedly increased the number of public and private institutions providing maternal and infant care, although some studies have shown a low capacity in decentralized municipalities given the insufficient levels of human capital related to the local health directives and the healthcare institutions ${ }^{8}$.

Maternal health has been a priority health issue worldwide for many decades. Most recently, it was the fifth Millennium Development Goal (MDG), which seeks to improve maternal health by reducing the maternal mortality ratio by three quarters by 2015 . Colombia adopted and adapted the MDG to its own context by committing to reduce maternal and infant mortality ${ }^{8,9}$. Additionally, the UN's Committee on Economic, Social, and Cultural Rights (CESR) declared that accessibility, availability, acceptability, and quality constitute four fundamental elements of the right to health, especially for women and maternal health ${ }^{10}$. In this context, quality is recognized as a fundamental aspect in the provision of healthcare services, and as Donabedian suggests, the quality of healthcare depends on obtaining the most benefits possible for medical care with the least amount of risk to the patient ${ }^{11}$. Within Colombia, Decree 1011 established the Obligatory System of Guaranteed Quality Healthcare within the SGSSS. It requires that service providers have the necessary technological and scientific capacity to guarantee their patients accessible, opportune, secure, and continuous services.

Despite international commitments to maternal health and the political strategies Colombia has set in place, the rates of preventable maternal morbidity and mortality in Medellín continue being a relevant health problem and merit investigation. Thus, the primary objective of this study was to analyze the characteristics related to the quality of maternal healthcare in specific institutions around Medellin from the perspective of expectant mothers, nurses, doctors, and administrators 
involved at different points along the chain of service provision.

\section{METHODS}

This qualitative study was conducted through the Facultad Nacional de Salud Pública (National Faculty of Public Health) at Universidad de Antioquia in Medellín between August 2008 and June 2009. We identified 18 public and private Healthcare Provider Institutions (IPS for the name in Spanish), affiliated with different Healthcare Promotion Insurance Companies (EPS for the name in Spanish), and included primary, secondary, and/or tertiary healthcare throughout Medellin offering a range of obstetric services and attending to a high volume of patients with diverse demographic qualities. Also included in the study were six EPSs, municipal and departmental health entities, and one academic institution directly linked to monitoring maternal healthcare in the city. Within these institutions we contacted doctors and nurses who had at least one year of specialized experience in maternal care and who were directly involved in offering maternal services or involved in the management of maternal healthcare services in the IPS, EPS, or health departments during the study period. In-depth interviews were conducted with 2-3 individuals from each of these institutions to collect a range of views.

Three focus groups were conducted with a total of 17 women who were either pregnant at the time of the study or had given birth in the past six months and belonged to the network of one of the institutions involved in the study where personnel were interviewed. These women were insured through the contributive or subsidized systems, different EPS, or did not belong to any health insurance network. Socioeconomic status and other demographic variables were not taken into consideration for selection criteria, and all participants went through an informed consent process.

Interview guides for both the individual interviews and focus groups were centered around the following topics: experiences from prenatal control sessions, delivery, and post-delivery care; referrals between institutions; aspects that influenced access to services; access to information, and familiarity with the rights and responsibilities of patients and providers; and recommendations for how to improve maternal health- care. The guides were pilot tested at the start of the study, then fine-tuned throughout the interviewing process to address new themes that emerged and merited inclusion.

All of the interviews and focus-group discussions were recorded and immediately transcribed. The transcripts were analyzed by using systematic coding and categorizing as proposed by Strauss and Corbin ${ }^{12}$, Miles and Huberman ${ }^{13}$, who suggest a careful review of each transcript's text to guarantee validity and reliability of the results. We applied two forms of triangulation:

1) information generated from the individual interviews with healthcare professionals was compared to the responses from focus-group discussions; and

2 ) the coding and categorizing was conducted and cross-checked by the three researchers working on the study, allowing for the qualification of the categories that emerged and helping us to identify when saturation was reached. Finally, the preliminary results were validated through the iterative process of revising the research instruments, meeting with mothers and providers, and reviewing the transcripts. Precautionary measures were taken throughout the entire study to protect the identity of all participants.

Limitations. The greatest limitation of this study is that it was only conducted in the city of Medellin and, thus, our results cannot be compared to the quality of maternal healthcare services provided in other cities even though the characteristics of the SGSSS are similar in all Colombian departments.

\section{RESULTS}

Impact of politics and government strategies addressing maternal healthcare. In the framework for the National Politics of Sexual and Reproductive Health in Colombia ${ }^{9}$, health authorities in Antioquia and Medellín have created a campaign for «Safe Motherhood.» This campaign is aimed at improving the coverage and quality of institutional maternal healthcare, strengthening the actions of surveillance and control to prevent complications, reducing maternal and perinatal mortality, as well as low birth weight and congenital syphilis ${ }^{14}$.

. The following are strategies implemented by «Safe Motherhood:»

- Cooperation between the municipal government 
and the NACER* group $^{15}$ from the School of Medicine at Universidad de Antioquia to achieve three main activities:

1) technical training, advice, and assistance for health workers in public and private healthcare institutions offering maternal care;

2) revision of severe cases of morbidity, such as postpartum hemorrhage, sepsis, and acute preeclampsia; and

3) implementation of an epidemiological surveillance program for cases of severe morbidity, maternal deaths, and children under 5 to prevent complications and maternal deaths with an emphasis on controlling obstetric hemorrhaging.

-Improve and expand the infrastructure and obstetric response capacity for the networks of public institutions in Medellín.

-Develop joint actions between the Sectional Director of Health in Antioquia, the EPS, IPS and academic sectors such as:

a) strengthening the Committee of Epidemiologic surveillance of maternal and perinatal deaths after 2007;

b) inter-institutional coordination;

c) active enrollment of pregnant women in prenatal care; and

d) creation of a plan for the certification of quality maternal care in the IPS as a requirement for accessing the contracts, including the design of a system for geographic reference and development of a model for prenatal home care, seeking to improve access and opportune detection of risks to enhance integral care throughout the city of Medellín.

Aspects affecting the quality of maternal healthcare. Of all those enacted, three political strategies to improve maternal care stand out: 1) the structure and organization of maternal services; 2 ) the characteristics of healthcare processes; and 3) the results and impact of care. Each one of these categories is described hereinafter.

1) Structure and organization of maternal services

* NACER is a group dedicated to reproductive health in the Department of Gynecology and Obstetrics and Universidad de Antioquia (U de A). It was associated with the CLAP group from Montevideo from 2003 to 2007, when it became a research, faculty and extension group at $\mathrm{U}$ de A.
-Limitations of the physical infrastructure: Even though IPSs have made an effort to improve maternal healthcare, the physical capacity of many organizations is weak. This includes a deficit of beds, supplies, fetal monitors, ambulances, and staff, which severely limit an institution's capacity to adequately attend patients. One nurse commented: «You call and call a tertiary care hospital to transfer a premature baby or a woman at risk of miscarrying and many times there are no beds available, so you are left with a bleeding patient, sitting in shock.» Another hospital administrator stated that «many of the insurance companies don't have contracts with other clinics and the patients have to deliver on a gurney because there aren't enough beds, let alone empty rooms, then after only 12 hours they are discharged.»

The imbalance between the supply and demand for delivery care, where demand is much greater than the supply, has created a saturation of patients throughout the system. This hinders the quality of care given that neither personalized care nor permanent supervision is guaranteed during prenatal visits, delivery, and postpartum follow-up visits. This leads to incorrect diagnostics of patients and mistakes in medical conduct. A mother commented that the hospital where she delivered «neglected me a lot. They told me that I had to wait for the gynecologist because they were very busy; by the time they took me to the delivery room I had a second degree laceration. I felt badly mistreated by the staff.» The effect of an institution's physical infrastructure on the experience of patients as noted by this woman:

"I could not deliver the placenta and it took over two and a half hours to admit me to the hospital. Once I actually arrived, they took a long time to go through all the processes to admitme. The doctors didn't even want to attend to me! I felt like I was going to die that day even though I wasn't conscious of everything that was happening.»

-Gaps in the information system: The poor maintenance of quality of information caused by the infrequent updating and cleaning of patient databases within the SGSSS contributes to the patients' limited access to care. Additionally, information about each institution's maternal health services is neither complete nor is it organized and systematized, resulting in failure to follow maternal patients as they move through different 
institutions for care.

-Insufficient quality and quantity of health care staff: Participants indicated that the majority of limitations in care came from the IPS in the form of a lack of personnel such as nurses, general physicians, and specialists. This is due to the institutions' strategy to reduce labor costs, limiting the coverage of care offered at any hour of any day. Staff does not regularly attend the training programs offered by the IPS and the Secretary of Health because they are often contracted through a cooperative for short periods of time. Employees, thus, have unstable positions and work for low salaries, with little incentives to improve their abilities. Thereby, the professionals and especially the doctors are doomed to maintain employment contracts with various institutions simultaneously and they work long, strenuous days-sometimes as long as 36-hour shifts. Doctors are continually under inordinate amounts of stress and extremely fatigued; hence, inhibiting their ability to provide the highest quality of care to their patients. In some cases, participants noted that they interacted with staff that were not trained nor enjoyed working with maternal patients. These factors have many direct implications on the feeling patients had about the quality of the attention they received. Some examples are listed below:

«Many people assisting patients are hired through Cooperative of Associated Work and cannot participate in trainings. Their high turnover rates give them little stability and no continuity so they do not feel like they belong at the institution where they are working; they don't even have time or make an effort to talk with the patients.» Nurse

«As a contracted worker you arrive at the IPSS at 5 pm and don't leave until 3 or 4 in the morning. The amount of patients coming through at these hours is impressive and the work is very difficult and bad. There will only be two doctors on duty in emergency care; while one patient is being treated another is dying in the waiting room.» Doctor

«There are places where there is nowhere near enough staff, only one obstetrician during 24 hours, because obstetricians are paid very little. That same doctor will be attending emergengy care patients, deliveries, surgery, and postpartum patients all at once. The staff is exhausted. The doctors are hired by 2-3 institutions at a time to earn enough money and they end up working for 36 hours straight, and it is not uncommon to find doctors sleeping during their rotation because they are so tired.» Nurse

On the positive side, several participants identified some institutions where the OB/GYN program functions well and offers better quality of care than in other places, given that these IPS have sufficient supply of staff workers who are trained, motivated, and interested in their work. These locations also have orientation programs for new personnel and recurring trainings for their staff. The patients affiliated to prepaid healthcare are guaranteed attention exclusively from an obstetrician and pediatrician.

\section{Characteristics of the treatment process}

-Fragmentation and lack of integration of attention: The process of receiving treatment is intimately tied to the aspects of the structure and organization of the services previously described. Integration and continuity of healthcare services is affected by the fragmented way in which the contracts are made between EPSs and IPSs. Given this situation, patients have to move between one institution and another to access the healthcare services they need, which affects their opportunity to receive treatment and increases the costs of the care received. It is also difficult for staff to track these patients and give back test results after they have moved to another institution-even if it is part of the services the EPS offers.

One nurse told us that «in Medellín we have evaluated 55 IPSs that offer prenatal care programs and 22 public and private institutions that attend births. A big problem is the fragmentation of services, where the pregnant patient has to go to one IPS for consultation, and then go to another for the sonogram, and yet to another for the medicine, so she has to pay for the transportation to get to all of those places». That same nurse noted how «the HIV tests and antigens always take a long time to process, when patients come for their second or third prenatal exam the results from their previous tests are oftentimes still not available».

Lack of integrated care in the predominantly clinical setting can also be found in the social and personal aspects of the patients' experience, such as their lack of knowledge about their health, especially regarding breastfeeding and family planning. This reveals a lack of coordination among institutions to address these social and personal situations of female patients. One 
mother discussed her inability to secure the care she knew she deserved:

Not only did they poorly attend my delivery at the clinic, but also at the Family and fiduciary commissioner when I went to file a complaint for interfamily violence. I arrived at 5:10 pm and saw the social worker at 5:20 who told the secretary that they couldn't see me because it was so late and she only worked until 5:30. I was six months pregnant with a high-risk pregnancy, I tried to complain but nothing happened.

-Ambivalence to regulations and protocols: Colombian norms to ensure the quality of maternal health care are considered strict, especially in Medellín. It is argued that staff and resources at many institutions do not comply with the protocol for immediate postpartum care. An example is that even though processes like monitoring of bleeding, uterine involution, and checking patient's vital signs every 15 minutes are considered effective ways to prevent maternal morbidmortality for postpartum hemorrhage; they are not always followed. One nurse noted: «Among the causes for maternal mortality are hemorrhaging due to a lack of transfusion products and errors during delivery. Upon promptly removing the patient from the delivery room they don't perform the necessary tests, the same happens with the early discharge of mothers who have recently given birth in order to make the bed available to admit others»».

In some cases, the way in which the norms are applied to the provision of maternal care limits accessibility, as well as the equality and the quality of the services. This happened in certain cases, as in those in which a newborn had delayed affiliation within the SGSSS and did not receive the necessary care; services were denied to those included and those not included in the POS, laboratory exams for a mother's partner were not covered by her insurance (in the case of tests for syphilis, which increases the risk of congenital syphilis), or the paperwork required by the EPS was not properly filled out to authorize services. All of these deviations from the standard protocol imply additional costs for users and their families. A nurse commented on how they «documented very painful maternal deaths of women enrolled in prenatal care and who were denied service because they did not have an Identification System for Subsidy Beneficiaries (SISBEN in Spanish) and were told that they had to be admitted as any other uninsured patient and pay.» Another nurse told us that «a lot of the medical performance is blocked by the system because it restricts many of the services that should be provided to patients»).

The program for promotion and prevention is recognized as facilitating early capturing of patients and integrality of services. Systemization of protocols facilitates management of the program, which improves quality and efficiency in some institutions. However, the pressures of competing costs among institutions, contention over prices, and priority given to specialists and subspecialists for the use of advanced technology undermine the importance of promotion and prevention activities.

While few IPS actually perform an internal audit or medical audit, some have a maternal-fetal board and conduct evaluations of adherence to the indicators and proposed goals. They then formulate plans to improve the training programs according to the results. Some IPSs also provide economic support to maternity patients who do not have the means to travel to their prenatal control visits. It is recommended that any IPS institution seeking to improve its indicators could undertake these types of activities.

-Limitations within the referral system: Referring patients among institutions offering maternal services presents many situations affected by the quality of service. These include, but are not limited to: administrative processes and paperwork to authorize referrals among EPS; insufficient response from the Regulatory Center due to a collapse in communication; lack of knowledge about emergency care among staff; limited number of ambulances available to transport expectant mothers; low capacity of primary care IPS to refer patients out, resulting in patients receiving inadequate treatment; inopportune and impertinent references to other institutions; and scarce development or inexistence of secondary care IPS that generate congested services at tertiary institutions. One doctor explained the issue as follows:

The problem in Medellin is that there are not enough beds in secondary and tertiary care insitutions and the referrals take a long time. We recently had a perinatal dealth because there was nobody to refer the patient to and when they arrived at the General Hospital, the baby was already dead. But yes, this is the worst thing that we have and it is not just with maternity patients, it is also 
the case with the rest of the patients because we can't always refer them out for the care they need.

The director of one of the local healthcare companies told us:

Ihave seen normal deliveries in high-level institutions that congest the specialized network; it is necessary for patients to be attended at the level, which corresponds to their need. The problem with the dysfunction of the network has existed for over 15 years and we haven't been able to solve it even though we have more institutions now than we did 10 or 15 years ago.

We observed that feedback from IPSs during referrals about diagnosis, treatment, and follow-up of patients was only done by several specialists. This problem was not as common in the IPSSs that were part of the EPS service network, given that it is much easier for the referral doctors to access information and follow up with their patients. The following quote from a doctor clearly illustrates this issue: «Usually, the $\mathrm{OB} / \mathrm{GYN}$ never refers out. It is rare for the $\mathrm{OB} / \mathrm{GYN}$ to conduct follow-up with the patients themselves, the patient's history simply stays at the institution from where they came and we base our treatment on what they tell us. But many times, patients do not understand what the OB/GYN told them».

Results and impact of care. Participants indicated that the factors related to lack of capacity, technology and medical supplies, lack of adherence to protocols, early discharge of patients to reduce costs and increase the productivity of the hospital beds, absence of basic care during birth and postpartum, among others lead to problems with the quality of care and results in complications or even deaths among pregnant patients and their babies. The low cost of maternal services discourages IPSSs from providing optimal care, especially during deliveries, stimulating unnecessary cesarean sections because they are more profitable. We observed that maternal care in Medellín is stagnated while it attempts to obtain a balance among productivity, efficiency, profitability, and competition, which affects all of the health services within the SGSSS, given the competitive market to which they are subject. Institutions that do not play this economic 'game' but might offer better services to their patients are penalized through this system and run the risk of bankruptcy.

A nurse summed up the faults in the system by saying: «Maternal care is discouraged because what we get paid is less than for other types of services. It is more efficient for many of the obstetricians to schedule cesarean sections, which is why the rate of cesareans in the city is around $40 \%$; very exaggerated, compared to the goal of WHO that is around $15 \%$. One could say that there is a market mechanism that is driving the high use of cesareans in Medellin.» That same nurse commented that «early discharges indicate that within maternal health care boosts the quality, in the economic sense. The WHO proposes that women should remain hospitalized for at least 24 hours after delivery, but here in Medellin we don't even guarantee 12 hours. Some women stay for as little as six hours so that one bed can produce three patients per day. The obstetric bed is very cheap, so healthcare providers get more than their money's worth».

As a result of the strategies set in place by Medellin's Secretary of Health with the NACER group Universidad de Antioquia, increased monitoring of maternal morbimortality is taking place and has improved the capacity of health personnel. This has achieved the greatest impact on the main cause of maternal deaths, postpartum hemorrhage, which is now the third cause of death and is considered an important achievement. However, although policies, programs, and efforts have been established throughout the different institutions to improve maternal care, several problems persist. These are:

a) the goal of insurance coverage of prenatal visits during the first trimester has not been achieved; thus, diagnosing congenital syphilis much later in gestation;

b) accumulation of appointments solicited with specialists, such as gynecologists and fetologists;

c) bitter moments during delivery that taint the quality of the rest of the service cycle;

d) congestion of the emergency care services and high occupancy in the hospitals; and

e) complaints of patients.

Participants believed that some aspects have limited the development of the policies and strategies established to improve quality. These include:

a) scarce leadership from the Antioquia Sectional Director of Health;

b) poor improvement of the service network's infrastructure from some private EPS, especially those whose administrative structure is centralized 
in Bogotá;

c) limited commitment by some institutions to the Safe Maternity strategy;

d) poor working conditions for the staff and insufficient human resources in terms of quality and quantity;

e) obstetricians' lack of attendance to required trainings;

f) absence of a support network for abandoned adolescents and mothers;

g) late capturing of pregnancies;

h) faults within the information system that make it difficult to monitor management and evaluation indicators;

i) low cost of obstetric care that progressively limits the availability of these services; and,

j) conflict among institutions derived during processes of contracting services, negotiating costs, and the demands of insurance companies.

\section{DISCUSSION}

International agreements have shown the importance of maternal healthcare to which Colombia has adhered and responded to by creating its own Sexual and Reproductive Health policies that involve strategies to improve maternal and perinatal healthcare. This has been the case in the Department of Antioquia, especially the city of Medellín, with the mandate for Safe Maternity without barriers. These strategies set the context for Legislation 100, enacted in 1993, that established a privatized healthcare system in Colombia as a way of increasing healthcare coverage to the population and improve access to health services. It also changed the subsidizing scheme from being based on supply to being based on demand for services in both public and private institutions, while attempting to stimulate the financial efficiency and profitability of the system and adversely affecting the development of public health programs. This study shows the deficits and difficulties in meeting maternal health policies. Most importantly, limitations of quality of care, in the structure and processes of care, can be understood through the way in which the services offered are trapped in a competitive market where profitability is the priority of healthcare providers. As a result, the quality of care is compromised and inhibits the efficacy of aims to reduce preventable maternal morbidity and mortality; aspects which have also been documented by other authors ${ }^{15,16}$.
Our findings suggest that healthcare institutions in Medellín experience limitations when providing maternal healthcare services related to inadequate infrastructure, materials, information systems, insufficient quality and quantity of health professionals, and the prioritizing reduced costs due to pressures from the competition and the low prices they are forced to charge for obstetric services. Even though many attempts have been made in Medellín to improve the network of maternal services, they have yet to be sufficient.

Within the healthcare institutions, activities that are not profitable are discouraged. This results in the early discharge of patients and the performance of unnecessary cesarean sections to increase profits and exposes patients to avoidable risks. For this reason, other studies suggest that the elevated levels of unnecessary procedures are indicators of the elevated level of medicalization of maternal care ${ }^{17}$, and that a model of medicalized care can be described as «that which promotes the use of unnecessary interventions, ignores the emotional necessities of pregnant women and contributes to an increase in the global costs of medical services ${ }^{18}$.

Legislation 100 introduced market mechanisms and competition between public and private institutions, competition that has been based fundamentally on prices and volumes of patients to increase their earnings. Thus, the contracts that EPSs make with the IPSs are based on the lowest price and fragment the services under financial criterion, without giving importance to the quality they provide. Every human being deserves to be born under conditions of dignity, which should be guaranteed by the State and society to protect women during their entire reproductive process. The importance and impact of these conditions makes them public goods and services. According to García and Caicedo ${ }^{19}$, public goods are not subject to the discretion of the consumer and are protected and promoted by the State to ensure the well-being of the population on an individual and collective level and ensured in different ways, such as laws, to verify their conduct and that they are considered public goods. Public services are those which are fundamental rights of the people, and, similarly, it is the responsibility of both the State and society to guarantee these goods and services to those who are not able to obtain them in the given market. Without access to these goods, people will find themselves seriously limited in their ability to survive 
and develop their abilities.

This study shows that despite the intentions of the government to enact policies protecting sexual and reproductive health, pregnant women in Medellin face problems related to access and quality of obstetric services. These services are influenced by economic pressures such as competition between insurance companies that supersede the provision of the quality of care to which all women have a right. This defies what was established in the international agreements such as the United Nation's Committee of Economic, Social and Cultural Rights ${ }^{14}$ for the four fundamental elements of right to health: accessibility, availability, acceptability, and quality. More importantly, within Medellín's healthcare context, deficits in quality maternal services do not comply with what is stipulated in Colombia's Constitution of 1991 and Colombian policies regarding maternal health ${ }^{16}$. Action must be taken to improve this inadequate system.

Conflict of interest. None of the authors has conflicts of interest related to this study.

\section{REFERENCES}

1. Torres Y, Montoya L, Cuartas J, Osorio G. Factores asociados a mortalidad materna-estudio de casos y controles. Medellín 2001-2003. Rev CES Med. 2005; 19: 19-45.

2. Quintero A. La mortalidad materna como indicador de impacto de la politica sanitaria en Colombia. 1985-2002. [Tesis de Maestría Salud Pública]. Medellín: Universidad de Antioquia; 2005. 120 p.

3. Burki S, Perry G, Dillinger W. Estudios del Banco Mundial sobre América Latina y el Caribe: más allá de centro: la descentralización del Estado. Washington, DC: Banco Mundial; 1999.

4. CEPAL. Anuario Estadístico de América Latina y del Caribe. Santiago de Chile. Accessed March 10, 2010. http:// websie.eclac.cl/anuario_estadistico/anuario_2009/esp/ default.asp

5. Alcaldía Medellín. Secretaría de Salud. Situación de salud: indicadores básicos 2005. Medellín: Secretaría de Salud; 2006.
6. Ministerio de la Protección Social, Fondo de Poblaciones de las Naciones Unidas, Organización Panamericana de la Salud. Plan de choque para la reducción de la mortalidad materna. Bogotá: Ministerio de la Protección Social; 2004.

7. Tricos que Ministerio de la Protección Social. Encuesta Nacional de Demografía y Salud. Bogotá: Ministerio de la Protección Social; 2007.

8. Molina G, Rodríguez C. Características de la descentralización en salud en tres municipios: Itagüí, La Ceja y Balboa. Rev Fac Nac Salud Publica 2002; 20: 7-22.

9. Ministerio de la Protección Social. Política Nacional de Salud Sexual y Reproductiva. Bogotá: Ministerio de la Protección Social; 2003.

10. Naciones Unidas. Cuestiones sustantivas que se plantean en la aplicación del pacto internacional de derechos económicos, sociales y culturales: disfrute del derecho a la salud en condiciones de igualdad. Ginebra: Consejo Económico y Social, Comité de Derechos Económicos, Sociales y Culturales; 2002.

11. Donabedian A. Garantía y monitoria de la calidad de la atención médica: un contexto introductorio. México: Instituto Nacional de Salud Pública; 1990.

12. Strauss A, Corbin J. Basics of qualitative research: Grounded theory procedures and techniques. Newbury Park: Sage; 1990 .

13. Miles M,Huberman A. Qualitative data analysis: An Expanded Sourcebook. 2a ed. Thousand Oaks: Sage; 1994.

14. Alcaldía de Medellín. Modelos para el análisis de la mortalidad materna y perinatal. Medellín: Secretaría de Salud; 2005.

15. Vargas J, Molina G. Calidad de los servicios y su relación con las decisiones en la atención en salud. En: Molina G, Muñoz I, Ramírez A (eds.). Dilemas en las decisiones en la atención en salud. Ética, derechos y deberes constitucionales frente a la rentabilidad financiera. Bogotá: Instituto de Estudios del Ministerio Público; 2009. p. 77-90.

16. Pazmiño S, Guzmán N. Control prenatal y su impacto en la mortalidad materna. Análisis de una tendencia, 1994-2004. Cali, Colombia. Rev Colomb Obstet Ginecol. 2009; 69: 12-8.

17. Langer A, Villar J. Promoting evidence based practice in maternal care would keep the knife away. BMJ. 2002; 324 : 928-9.

18. Tracy S, Tracy M. Costing the cascade: estimating the cost of increased obstetric intervention in childbirth using population data. BJOG. 2003; 110: 717-24.

19. García J, Caicedo B. La Dimensión económica y política de los servicios de salud: un aporte general para el derecho a la salud y la justicia sanitaria en Colombia. Rev Fac Nac Salud Publica. 2002; 20: 117-33. 